\title{
Perspectives on cheating at a Thai University
}

\author{
David Young
}

\author{
Correspondence: dvyoung444@ \\ gmail.com \\ Phra Nakorn Sri Ayutthaya Rajabhat \\ University, Phra Nakorn Sri \\ Ayutthaya, Thailand
}

\begin{abstract}
One of the major problems facing Thai education at the university level is that of academic dishonesty. While newspapers often report upon individual and group cases of university-level cheating, there has been little research done to determine the reasons behind the dishonesty of Thai students as well as the extent and implications. In addition, surveys have shown that a majority of both students and teachers do not regard cheating as a serious offense. This study presents the reasons cheating occurs among Thai university level students through a discussion of cheating within Thai culture. By focusing upon three aspects of the Thai character, namely sanuk, mai pen rai, and a present-oriented frame of reality as well as the persistence of corruption in society, the rationale behind academic dishonesty becomes apparent. In addition, a survey of 106 undergraduate students of Phra Nakorn Sri Ayutthaya Rajabhat University was conducted to determine the prevalence of these aspects and whether students had engaged in cheating. Interviews were also conducted among university teachers to ascertain their opinions on university level cheating. A discussion follows in which possible strategies are proposed to combat cheating at the university level.
\end{abstract}

Keywords: Thailand, Cheating, Education, Reform, Plagiarism

\section{Background}

Cheating is not a phenomenon unique to Thailand. In the past year alone, occurrences of cheating have been discovered at universities in Britain, Japan, Sweden, Turkey, and Iran. According to a survey in the Science and Engineering Ethics Journal, over one third of undergraduate students at a top research university in America admitted to some form of cheating (Klocke 2011). What separates the stories of cheating and plagiarism that appear regularly in newspapers across Thailand from those of other countries is the fact that so few Thai appear to be outraged by these persistent scandals. In the words of Taweekun Rawaheep, the acting rector of one of Thailand's most prestigious learning institutions, Ramkhamhaeng University, "Ramkhamhaeng University considers cheating in exams by students to be trivial. It is common in all exams" (Bunnag and Tumcharoen 2002, para. 4). In recent years, incidents of academic dishonesty have been reported at Ordinary National Education Test at exam centers in Bangkok (Bunnag 2010), during English tests required for bachelor's degrees, (Daglas 2003), and at national university entrance exams (Wong-Anan 2008). In addition, according to records at Thammasat University, a total of 240 undergraduate and graduate students were caught cheating on exams for the 1997-2006 academic years. This is an increase from 113 for the 1987-1996 academic years and 56 for the 1976-

(c) 2013 Young; licensee Springer. This is an Open Access article distributed under the terms of the Creative Commons Attribution License (http://creativecommons.org/licenses/by/2.0), which permits unrestricted use, distribution, and reproduction in any medium, provided the original work is properly cited. 
1986 academic years. In the words of university disciplinary officer Waleeporn Tanthapanich, "university students today do not hold honesty in high regard" (Bunnag 2007, para. 6). Cheating, it seems, is not so much a random occurrence as it is a part of Thai education.

According to Bangkok Post Opinion column writer Vanijaka (2011) "Cheating and corruption is the norm at all levels of society, and incompetency is the sum of our failings" (para. 12). Indeed, over the course of the past decade, cheating scandals have surfaced in the Royal Thai Police examinations (Punyawan 2010), army entrance exams, ("Thailand students" 2005), and even the three grades of Dharma studies exam - including the Pali language exam - in the institution of Buddhist monks (Visalo 2008). It is from Thailand's university system, however, that the greatest number of cheating scandals can be seen and it is here perhaps that the "sum of failings" originates. With a lax attitude and a blind eye towards academic dishonesty at the university level, it is entirely possible that some individuals in whom Thai society places their safety and trust are under-qualified if not wholly unqualified for the positions they hold. Although it is impossible to determine the number of Thai professionals who have earned their positions through dishonest means, it can be argued that cheating lies at the heart of every undeserved degree. In a previous essay, the author examined the role of Thai culture and its negative effects upon learners of English (Young 2010). In this report, a deeper examination into a particular aspect of Thai society will be conducted - that of university-level cheating - and an attempt will be made to discover both the reasons and extent of its prevalence among Thai university students. In addition, the question will be raised as why significant condemnation of the crime fails to exist among teachers, administrators, and parents. To achieve this, a literature review discussing factors relevant to the moral development of the Thai student with regards to their cultural milieu will be presented. Following this will be an exploration of how attitudes and bias within the culture show that academic dishonesty in Thailand does not follow the long-held perceptions of cheating as in other parts of the world. Findings will then be presented from a survey of 106 students of various majors currently studying at Phra Nakorn Sri Ayutthaya Rajabhat University regarding factors that may lead to academic dishonesty. This is followed by in-depth interviews with teachers of the university on their experiences and positions regarding cheating. Finally, the report will conclude with a discussion on the data received and draw some conclusions about cheating in Thailand. It is hoped that by drawing attention to the problem, cheating will eventually come to be regarded as with the seriousness that it merits by both educators and students.

\section{Literature review}

\section{What is cheating?}

Before we can delve into the factors behind cheating in Thailand, it will perhaps be helpful to define what is meant by "cheating." Cheating is usually defined as a series of practices that are considered illegal, unethical, immoral, or in violation of the regulations set by the course or institution. Academic cheating, in the words of Davis et al. (2009), can be defined as "acts committed by students that deceive, mislead, or fool the teacher into thinking that the academic work submitted by the student was a student's own work" (p. 2). Of course, these definitions come into question when issues of transparency are raised. Is it cheating, for example, when parents or peers assist the student in 
completion of homework without the teacher's knowledge? While questions such as these raise valid arguments as to one's perspective of cheating, a basic classification of cheating as it is typically understood by Thai university students and teachers will be sufficient for the purposes of this essay.

\section{Cheating in Thailand}

While there are numerous surveys and theories concerning the motives behind student dishonesty, (Whitley 1998; McCabe 2005; Simkin and McLeod 2009), the majority of studies concentrated upon cheating within a non-hierarchical Western society. Rather than expound upon the motives behind student cheating at a British or American University, the focus of this paper will instead concentrate on characteristics exhibited by the typical Thai university student. This is not done to disqualify any previous findings, but rather because it is the author's belief that academic dishonesty in Thailand can only be understood through an analysis of socio-cultural factors that come into play and exert an influence upon both students and teachers in their beliefs and views on the matter.

In a previous study on engineering students' attitude towards plagiarism, surveys were conducted among Thai undergraduate students to determine rates of plagiarism in terms of goal orientation (Songsriwittaya et al. 2009). While the majority of students surveyed viewed individual competence as the primary means of mastering a subject matter, results from a study of plagiarism behavior indicated that students plagiarized in order to receive a high grade. The authors attributed this discrepancy to Thailand being a "relationship oriented" society in which copying from a friend or acquaintance may not be regarded as plagiarism.

Although the authors raise a valid point, further consideration of the culture in which Thai students are educated show that relationships are only a part of the picture. In the author's previous paper, a study was conducted on the effects of culture upon Thai learners of English (Young 2010). One of the conclusions reached was that the hierarchy of Thai society provided a negative influence upon learners due to the unjust practices of rewarding those higher on the social ladder while forcing those on the lower rungs of society to fall in line under the leadership of "higher-ups." The resulting society was one where conformity, respect, and obedience were prized over hard work, innovation, and fairness. While that study looked at the inner workings of Thai society from the "top-down," this report will examine the hierarchy from the position of one lowest on the social ladder - the Thai student - and attempt to determine what factors influence them to resort to dishonesty as a means of achieving a higher status.

\section{Growing up Thai}

Following the work of Piaget and Kohlberg, it has become a widely held notion that emotional development is closely linked to moral development in children. In Thailand, emotional and behavioral problems displayed by children in Thai classroom have created buzzwords such as "autistic" and "hyper" among Thai teachers with little understanding as to the true nature of the disorders. This appears to be a trend that shows little sign of abating as counselors and child therapists remain largely absent from Thai schools and society. While the number of children suffering from emotional problems has yet to be determined, studies have been made to clarify the source of these 
problems in Thailand (Isaranurug et al. 2005; World Bank 2011). More revealing, however, was a study of behavior and emotional problems among Thai adolescents carried out by Weisz et al. (1993), which found that cultural pressure in the areas of self-control, emotional restraint, and social inhibitions were determined responsible for over controlled problems (fearfulness, sleep problems, somaticizing) without affecting under-controlled problems (disobedience, fighting, arguing). This self-control and emotional restraint can be directly related to the cultural tradition of maintaining a "cool heart" (jai yen) and controlling or suppressing one's emotions for the benefit of a harmonious society - a concept children learn at an early age, but do not really master until they have matured.

In relating emotional development with morality, a 2011 survey by the Health Systems Research Institute of children's emotional and moral health found that there was an increase among children in the 10-14 age group who felt cheating was acceptable to pass exams or win games as compared with the previous decade. In addition, children of all age groups fared worse in compliance, empathy, emotional control, and critical thinking ("Why Thailand" 2011). From this data, one may conclude that the Thai child with emotional or behavioral problems will most likely enter adulthood with a sense of morality that has not been developed to its full potential.

\section{The cultural environment}

To provide a framework for the culture in which academic cheating occurs, it will be useful to examine the environment in which Thai children are raised and note the influences that have an impact upon their moral upbringing. This is not done to generalize or predict the Thai child's frame of mind, but rather to obtain a basic understanding of the world they inhabit.

As mentioned, Thai society is based upon hierarchy. The young respect the old, the student respects the teacher, and a low level office worker respects their superiors. "Respect" is a somewhat loaded word in the case of Thailand, however, as it can signify a multitude of cultural rules ranging from the order in which the initial show of respect (the wai) is given among individuals to the restrictions placed upon those on the lower end of society in regards to questioning the instructions, orders, or decisions of those above them. While this arrangement of society has proven to be a hindrance to language learning (Young 2010), this study shall examine further aspects that inadvertently contribute to an environment of academic dishonesty. To do this, the maintenance of harmony in society will be examined through a pair of concepts that are unique to the Thai character, sanuk (fun) and mai pen rai (never mind, it doesn't matter). It will then be argued that Hofstede's power index ranking of Thailand as a nation of long-term orientation indicates a discrepancy rather than a true reflection. Finally, the study shall conclude with an overview of corruption in society as well as the no-fail policy of Thai universities.

\section{The Thai character}

Sanuk

In Bousquet and Patamadit's report on the learning process in Northeast Thailand (2005), they concluded that a character trait that nearly all studies have found among the Thai is that of sanuk, or - roughly translated - the enjoyment of living. One's 
ability to provide a pleasant atmosphere greatly enhances their acceptance in society. This has created the perception of Thailand as the "Land of Smiles" and the Thai as an easygoing people more fond of pleasure than hard work. In Komin's study of the psychology of the Thai (1990), it was found that the importance placed upon sanuk was related more to the maintaining of interpersonal relations rather than as an end onto itself. In the field of education, one of the major points of teacher reform made by the Office of the National Education Committee (ONEC) in 2002 was to foster joy in learning by emphasizing sanuk in the classroom (Fry 2002). While there is a general assumption that the incorporation of "fun" in a classroom enhances the learning process, there is a hidden danger involved. As Okan observed, “...equating learning with fun suggests that if students are not enjoying themselves, they are not learning. In other words, learning becomes an obstacle that learners need to overcome" (2003, p. 258). To Bloom and Hanych, "such an approach doesn't promote learning; it trivializes the learning process" (as cited in Okan 2003, p. 258). Furthermore, games do not promote the process of learning as something to be preserved (Okan 2003). This problem is compounded when we take into account the lack of an essential skill among both Thai educators and students - that of critical thinking.

While there are varying definitions of critical thinking, it is generally agreed upon that characteristics of a critical thinker include questioning assumptions, the desire to remain well-informed, open and fair-mindedness, and a willingness to reconsider viewpoints. The contrary, as put forward by Scriven and Paul (1987), is one who merely acquires and retains information along with possessing skills simply for their continued use. As Cleary points out in his appraisal of Thai students, "From the first grade, students are taught to "repeat after me", recite a few sums, and believe every word that comes out of their teachers' mouths in quiet obedience" (Cleary 2007). Without the ability to analyze, question, and challenge information presented by the Thai teacher, a "fun" lesson may be seen as just that, with entertainment becoming the detrimental factor in learning, thus diminishing the importance of the learning process as well as turning one's grade point average into an indication at how well one "played" rather than achieved.

\section{Mai pen rai}

Mai pen rai is often a difficult expression to translate. Yet it is so deeply engrained within Thai society that it is often the first expression that foreign visitors learn. It can be translated as "never mind," "don't worry about it," "forget it," or "don't bother." Yet it also implies the assumption that since problems and adversary will eventually become better, worrying about them will achieve nothing (Cai and Shannon 2010). Moreover, there is the indirect connotation that one must surrender to forces beyond one's control, invoking the idea of karma (McCarty et al. 1999). This idea is expounded upon by Dr. Daniel Saengwichai (1998) who argues that the philosophy of mai pen rai "has implanted deep within the people a sense of passive resignation to fate, thus impairing their ability to counteract the problems and to seek for solutions" (para. 2).

From a psychological standpoint, the "passive resignation" that Dr. Saengwichai refers to can be attributed to the concept of learned helplessness, a condition in which a person feels unable to change their circumstances. When considering the Thai student who has attended English classes from an early age yet still cannot speak with basic fluency, we can understand how learned helplessness can set in. Although initial studies 
by psychologists such as Martin E.P. Seligman indicated that learned helplessness was a factor of depression, it was soon discovered that not all students who had acquired learned helplessness were depressed. Seligman postulated that this was due to different dimensions: personalization, pervasiveness, and permanence. A statement such as "I am stupid," for example, could be considered internal, universal, and permanent. "The English teacher gave me a hard test on Friday," however, could be seen as external, specific, and temporary. (His Yen 1998).

When applying these theories to the Thai university student unable to master the basics of English, we can assume that the level of learned helplessness is pessimistic as opposed to optimistic. Rather than externalizing frustration or showing disapproval of a superior's decision - both of which are prohibited by cultural norms - the Thai student will likely take the blame onto themselves. Yet despite Seligman's findings, depression is not a major problem among Thai students (Dubas and Petersen 2003). This is perhaps due to the fact that a "resignation to fate" in the engrained philosophy of mai pen rai promotes the idea that areas of learning are not challenges, but insurmountable barriers that no amount of effort can overcome. When academic success depends upon passing or failing in the face of these obstacles, the students' resorting to dishonesty can be more clearly understood.

\section{The present-oriented mindset}

One of the reasons students cheat is that it offers a quick and easy route to obtaining a good grade. A student who cannot see beyond immediate goals is obviously more prone to academic dishonesty than one who is aware of future consequences for acts committed in the present. This second section surveying the factors of the Thai character in regards to academic dishonesty sought to determine whether Thai society is one of long or short term orientation.

One of the dimensions of national culture added to Geert Hofstede's original four was the dimension of Long-Term Orientation, which was strongly intertwined with the teachings of Confucius. Some of the characteristics of a society exhibiting high longterm orientation are as follows:
a) Persistence and perseverance
b) Adaptation of tradition to new circumstances
c) Most important events in life will occur in the future
d) Students consider "persistent" an important personality trait

A society of low long-term orientation, however, exhibits the following characteristics:
a) Quick results expected
b) Protection of one's "face"
c) Respect for traditions
d) Students consider "persistent" not an important personality trait (Hofstede 2001)

In addition, long-term orientation has been identified with virtue whereas short-term orientation with truth. As Clark (2005) explains, 
A short-term view of results occurs when we know what result we want, thus we are willing to play with the truth to get it. A long-term view of results mean that we will get it when we get it - it is more important to find the greatness in our results than to find the result that we want (para. 8).

While countries such as China, Japan, and Taiwan rank in the top five for long-term orientation, Thailand's rating for this dimension is 56, which is still above average. Yet even the most superficial of observations of society will reveal that the majority of Thai lean away from Hofstede's parameters of high long-term orientation and toward the low. How then, does one explain the long-term orientation ranking of 56? Rather than an indication of a nation "straddling the fence," between short-term and long-term orientation, this may instead point to a society at odds with its future. As can be seen in education policies highlighting the virtues of Thai handicrafts, Thai dance, and Thai classical music, it is clear that the older generation continues to cling to a cultural past as a means of instilling virtue in the young. The issue is not whether these traditions are important, but rather the feasibility of cultural traditions ability to compete with video games, Facebook, cell phones, and other instruments of modern technology providing immediate gratification in which the younger generation of Thailand has embraced. In the words of Klausner (2005), “...the traditional values of the past do not represent the social and political reality of the present” (para. 17).

In discussing the political landscape of Thailand, Chutvachana (2009) writes, "The biggest joke about the failure of the Thais, is that Thais have a "Short" memory span" (para. 1). Indeed, a low short-term orientation appears to be a characteristic of a majority of Thai that is widely known but rarely acknowledged.

\section{Societal factors \\ Corruption}

In the 2011 Corruption Perception Index (CPI), Thailand ranked 80 out of 183 countries. According to the index, ten points indicates a country has a low-corruption level, while zero indicates a high-corruption level. Thailand received 3.4 points (Li 2011). According to Crittenden et al. (2009):

While country corruption does play a significant role in the evolution of a cheating culture, there is a difference between what students in corrupt countries will do and in their evaluation of others. Thus, it is not okay to 'do as I do', but to instead 'do as I say.' (2009, p. 343).

Corruption has inarguably been a problem that has plagued Thailand for many years. According to a recent Suan Dusit Poll, corruption and political exploitation were the biggest concerns for the year 2012 (“Poll," 2012). In a 2010 ABAC poll on people's views on government corruption, 1,349 households in 17 provinces confirmed that a majority of the population believe corruption is prevalent in the government. What is more striking, however, is that 76.1 percent of those surveyed accepted corruption in the government for the sake of prosperity and welfare of the country. 67.1 percent of students agreed that corruption was acceptable provided there were benefits for them as well (Saiyasombut 2010). 
In addition to politicians, lawmakers, police, and soldiers have been rated the most corrupt groups in Thailand. According to those employed within the state sector, highway and traffic police, Customs Department officers, and Tambon (local government) administration staff are all involved in corruption, usually in the form of kickbacks to "speed up their services" ("Thailand Remains," 2011b, para. 8).

In the field of education, what stands out is not the schools, but parents who employ various methods of dishonesty to ensure their children's success. At a prestigious elementary school in Phra Nakorn Sri Ayutthaya, the author has witnessed teachers receiving lavish gifts from parents in the hopes of "bumping up" their child's grade. In preparing for tests, examination papers cannot be taken to local print shops to be copied for fear that parents have bribed employees to make extra copies to give to them in secret.

The message is pertinent. Whether it is in the form of bribery, kickbacks, extortion, or a selective application of laws, the lessons that parents and society instill in children from an early age is that hard work and academic achievement are not always the paths to success and may, in fact, be a waste of time and effort if one is lacking the financial resources to ensure a continuing education. In addition, the perseverance of a society in which corruption is not regarded as a serious matter and instead offers an alternative to hard work as a means of solving problems must be considered a factor in students' decision to commit academic dishonesty.

\section{The no fail policy}

Now that we have observed cultural and societal factors that contribute to the Thai students' decision to cheat, it is necessary to examine the role of the teachers with regards to the potential for academic dishonesty to occur in the classroom. Specifically, this involves a policy that a majority of university Thai teachers are bound to follow, the no-fail policy. The basic ideology behind the no-fail policy is to keep students within their age group and advancing in grade regardless of academic performance. It thus falls upon teachers and schools to provide extra educational support to ensure the student is sufficiently prepared to enter the subsequent grade level. While various countries have adopted a no-fail policy, it remains a controversial topic as many parents and educators feel that it has a negative impact on student motivation and reduces the desire to excel (Halligan 2011).

While one may debate the pros and cons of the no-fail policy, there are issues that should be taken into account when considering the feasibility of implementing this policy in Thai universities. Factors such as large classes, teacher workloads, and the lack of proper training to ensure that the teacher is an expert in their subject can all turn the good intentions behind the no-fail policy into simply passing the burden of an underachieving student onto another teacher. Various observations made by the author in over ten years of teaching in Thailand have revealed noteworthy instances of the no-fail policy. At a leading primary school in Ayutthaya for example, students who failed an exam were forced to take a re-test in which teachers dictated the answers. Furthermore, in a university setting, foreign staff members who were unaware of the no-fail policy have been asked by high ranking administers to change students' grades, allowing them to pass regardless of academic achievement.

With this view in mind, the decision of the Thai teacher to allow or overlook academic dishonesty among students becomes more understandable. We can see that 
it is less a matter laziness or lack of moral integrity on the part of the Thai teacher, but rather being part of a system that does not allow the freedom to administer grades as they deem to fair. Nor are they given the time, classroom setting, and necessary skills to provide proper support for the failing student.

When observed as a part of a broader framework, the no-fail policy can be seen as part of the "lax discipline" that many educators attribute to the rising rates of cheating within universities. As Thammasat University Disciplinary Officer Waleeporn Tanthapanich observed, in an era when the university employed expulsion as punishment for academic dishonesty, only one student was caught cheating for a single academic year. Today, where punishment consists of a one-year suspension and community service, cheating is inevitably on the rise (Bunnag 2007).

\section{Methods}

To obtain a general idea of the climate of academic dishonesty in Thailand, we turn our focus upon a single university to determine the extent of cheating as well as the reasons for its persistence in Thai society. Phra Nakorn Sri Ayutthaya Rajabhat University is a medium-sized public university with a current student body of approximately 6,000 students and 300 staff members. As of July, 2011, the university ranks 55 on the Webometrics Thailand university ranking within Thailand and 3,511 worldwide ("Thailand best," 2011a). The university, as well as Rajabhats in over half of Thailand's other 77 provinces, was originally a teacher training college which only achieved university status in 2004. Nevertheless, a majority of students who study will likely to become future educators themselves. Given the relative ease of admission and the low cost of tuition, it may be noted that enrollment is mostly local, appealing to students who wish to further their studies but cannot afford to attend or academically compete in higher ranking universities.

\section{Participants}

106 undergraduate students of Phra Nakorn Sri Ayutthaya Rajabhat University participated in the survey. The students came from varying fields of study as can be seen in Table 1.

Students were asked to complete a questionnaire based on a typical five-level Likert scale. The subject of English was selected due to the fact that all of the participants had previously studied English before attending the university, and were currently enrolled in revision classes of Basic English. All questions were translated into Thai to ensure comprehension.

Table 1 Variety of survey participants

\begin{tabular}{|c|c|c|c|c|c|}
\hline Field of study & Year & Subject of study & Male & Female & Tota \\
\hline Business Computer & Sophomore & English for Communication & 8 & 14 & 22 \\
\hline Social Studies & Sophomore & English for Communication & 16 & 24 & 40 \\
\hline Occupational Health & Sophomore & English for Communication & 1 & 15 & 16 \\
\hline General Education & Sophomore & English for Communication & 15 & 1 & 16 \\
\hline Japanese & Junior & English for Secretary and Office Management & & 12 & 12 \\
\hline Total & & & 40 & 66 & 106 \\
\hline
\end{tabular}


In addition, nine teachers were also interviewed on their thoughts and opinions regarding student cheating and the no-fail policy.

\section{Instrument}

In order to determine whether the Thai characteristics mentioned in the literature review above were prevalent in students and had any bearing upon the decision to engage in academic dishonesty, the instrument used was a questionnaire written by the author. Questionnaires were administered to students during class time to determine attitudes towards teaching methodologies, self-perception with regard to a lack of English language ability, and participation in academic dishonesty.

\section{Research questions}

(1)Attitude towards learning ("Learning should be fun," "Teachers should use games and activities while teaching").

(2) Self-perception (“I can't speak English fluently because I'm not smart," "I can't speak English fluently because I have bad teachers").

(3) Short-term orientation ("Getting good grades is the most important part of education").

(4) Academic dishonesty ("I've cheated on tests," "Cheating is OK if you don't get caught," "I know people who have cheated on tests," "Teachers don't care if students cheat on tests").

\section{Hypothesis}

(1) Thai students feel that learning should occur in an environment of sanuk. A "fun" lesson is perceived as having more relevance than a challenging one. Games and activities are necessary to alleviate boredom.

(2)Learned helplessness places the current inability of the Thai student to master English squarely upon the individual student and not the teacher.

(3) Students exhibit short-term orientation in placing importance on good grades rather than learning.

(4) Students have cheated and their perception of educators is that of an indifference to cheating, as that would create more problems than it would solve.

To give further consideration to the question of cheating, nine teachers were interviewed with the following questions used as a basic framework.

(1)What is your position on student cheating?

(2)How often do you encounter student cheating?

(3) What procedures do you take when you encounter student cheating?

(4)Do you think student cheating is a serious problem at this university?

(5) Why do you think students resort to cheating?

(6) What measures do you think can be taken to prevent student cheating?

(7) What is your opinion of the no-fail policy? 


\section{Results}

\section{Students}

As can be seen in the following table (Table 2), a strong majority of students felt that learning should be fun. In addition, they expressed the notion that games and activities should be incorporated into the classroom learning experience. Students furthermore admitted to feeling stress when failing a subject. While assignment of blame for the students' inability to speak English fluently leaned slightly towards placing blame upon the student themselves, a great majority disagreed with placing blame upon their educators. There was also a strong majority that supported the idea that the obtainment of good grades was the most important part of education. For the questions involving cheating, most students preferred to remain neutral, with only slight disagreement on any involvement in actual teaching. On the contrary, there was some agreement concerning the knowledge of others cheating. The majority of students also chose to remain neutral or expressed disagreement on the topic of the indifference of teachers regarding cheating.

\section{Teachers}

In interviews with nine teachers regarding their opinions on cheating, 100\% encountered student cheating on a regular basis. In disclosing the forms that cheating took, all of the teachers agreed that it was in looking at each other's test papers and exchanging answers during exams. In addition, all of the teachers indicated that upon encountering student cheating, they first issued a "warning." There was some divergence in levels of severity however, when students persisted in cheating following the initial warning. This ranged from allowing the students to re-test at a later date to immediate test failure. There was also complete agreement that cheating was a problem at the university. When discussing the reasons behind student cheating, a majority of those interviewed blamed a general laziness on the students' part to prepare for the test with only two of the nine teachers indicating that roots of the problem may lie deeper. On the topic of preventative measures, all of the teachers were in agreement that stricter disciplinary measures needed to be taken to ensure that students faced the consequences of their actions. Finally, when asked about the no-fail policy, opinions were divided. While two of the teachers considered it a beneficial policy, five flatly stated that it hindered rather than enforced positive learning

Table 2 Analysis of student questionnaire

\begin{tabular}{|c|c|c|c|c|c|}
\hline Questions & S. Agree & Agree & Neutral & Disagree & S. Disagree \\
\hline Learning should be fun & $78 \%$ & $11 \%$ & $1 \%$ & & \\
\hline Teachers should use games and activities. & $43 \%$ & $47 \%$ & $9 \%$ & $1 \%$ & \\
\hline I can't speak English fluently because I'm not smart. & $19 \%$ & $23 \%$ & $27 \%$ & $12 \%$ & $19 \%$ \\
\hline $\begin{array}{l}\text { I can't speak English fluently because I have poor } \\
\text { teachers. }\end{array}$ & $3 \%$ & & $12 \%$ & $8 \%$ & $77 \%$ \\
\hline $\begin{array}{l}\text { Getting good grades is the most important part of } \\
\text { education. }\end{array}$ & $52 \%$ & $32 \%$ & $12 \%$ & $2 \%$ & $2 \%$ \\
\hline I've cheated on tests. & $4 \%$ & $8 \%$ & $36 \%$ & $20 \%$ & $32 \%$ \\
\hline Cheating is OK if you don't get caught. & $17 \%$ & $7 \%$ & $40 \%$ & $14 \%$ & $22 \%$ \\
\hline I know people who have cheated on tests. & $25 \%$ & $22 \%$ & $29 \%$ & $13 \%$ & $11 \%$ \\
\hline Teachers don't care if students cheat on tests. & $1 \%$ & $5 \%$ & $33 \%$ & $23 \%$ & $38 \%$ \\
\hline
\end{tabular}


habits. Furthermore, two teachers indicated that although they disagreed with the policy, they understood that it was necessary to give students further opportunities for improving themselves.

\section{Discussion}

\section{Students}

As shown by the results of the questionnaire, Thai students feel that sanuk is an important part of the learning process. This reflects Komin's (1990) findings of the importance of maintaining interpersonal relations between the students and their teachers. While there is certainly a necessity to encourage a "joy of learning" in the classroom, the nearly overwhelming agreement that teachers should use games and activities to impart knowledge may also be indicative of an intellectual immaturity among university students.

Students mostly indicated neutrality or agreement when placing blame upon their inability to speak English fluently upon their intellectual ability. However, nearly all disagreed with placing blame upon their teachers. This supports the hypothesis that there is some amount of learned helplessness in Thai students. In addition, a high rating of students in agreement with the statement "Good grades are the most important part of education" is indicative of short rather than long-term orientation.

On the subject of cheating, it can be seen that most students preferred to remain neutral, with only a small percentage admitting to academic dishonesty or whether cheating is permissible if there are no repercussions. It should be noted however, that only a minor percentage expressed disagreement when asked whether they know someone who has cheated on tests. A majority of students also expressed neutrality or disagreement on their perceptions of teachers' indifference to cheating.

\section{Teachers}

With regards to cheating, diversity of opinion among interviewed teachers seemed to coincide with the number of years teaching. While teachers with more than ten years of teaching experience found cheating "unacceptable," other teachers with less than five years of teaching experience showed more leniencies in dealing with student cheating, often by issuing verbal warnings and - as one teacher reported - allowing cheating students to "re-test" at a later date.

When asked why they thought students resorted to academic dishonesty, there was once again divergence among the younger and older teachers. Teachers with less than five years of teaching experience felt that the problem laid with the student. As one teacher stated, “Students are lazy. They don't do the reading assignments and when it comes time to take the test, they just put down any answer" (O. Kriangsak, personal communication, January 31, 2012). Teachers of more than ten years of teaching experience, however, looked beyond individual students and see the problem as societal. As one teacher bluntly stated, "Family is the start of the problem" (G. Proongwetch, personal communication, February 2, 2012). And from another, "Social values at present have changed. In the past, you had to work hard. Today, students don't know right from wrong. If it is easy, it is good" (J. Klaimook, personal communication, January 31, 2012).

When asked about their thoughts in curbing university cheating, all of the interviewed teachers were in agreement that discipline was lax. As Kruu On stated, 
"We must use discipline so students are afraid to do it next time" (O. Kriangsak, personal communication, January 31, 2012).

The largest disagreements in opinion came when asked about the university's no-fail policy, with one teacher claiming to disregard it entirely and another claiming that it was a good policy as it forced teachers to look at other factors such as class participation and homework when determining grades. It was in the opinions of the long-term teachers that displayed the greatest disapproval. Yet the disapproval was not so much with the policy as with the system that begot it. In the words of one teacher, "If students stay (at the university) long, parents will be angry" (M. Hoopreumsuksombat, personal communication, February 1, 2012).

In general, it appeared that teachers with more teaching experience had less tolerance for academic dishonesty. This is perhaps due to consistent encounters with student cheating and a general lack of support from the university that would allow them to enforce stricter discipline. An additional lack of condemnation from parents in regards to student cheating may also account for the increase of condemnation.

\section{Preventative measures}

While a lax attitude towards academic dishonesty was cited at both a local and national level, it also be seen that the cultural milieu of Thailand - from the deep-set traits of sanuk, mai pen rai, and a present-oriented frame of mind to the prevalence of corruption in society and no fail policies at universities - plays a role in shaping the students decision to cheat. As teachers have stated, stricter consequences for cheating would be a step in the right direction. This raises the question, however of how strict should the discipline be? Additionally, would a university known for a "zero-tolerance" policy on cheating find itself under attack from parents? When considering the dilemma of teachers who must abide by rules set by universities which in turn rely upon parents for financial support - it is easy to see how cheating cannot be solved by stricter policies alone. Yet rather than view cheating as something that needs to be stamped out, it would perhaps be of further benefit to empower students with the decision-making skills that would allow them to realize the consequences of academic dishonesty before committing it. As this would involve the inclusion of critical thinking in the classroom in conjunction with the teaching of moral and ethical norms from the very earliest of ages, the question of just how feasible it is in a country where hierarchy forms the very fabric of society.

Still, this does not imply that cheating among university students in Thailand cannot be overcome. With a gradual shift away from value placed upon grades and focused upon learning, Thai students may be less inclined to resort to the obtainment of good grades through dishonest methods. As Teddi Fishman, director of the Center for Academic Integrity at Clemson University, states, "If improving themselves is the actual goal, then it doesn't make sense to cheat" (Heagney 2009). Another means of maintaining honesty is to enforce a school honor code (Bassett 2004). The theory behind an honor code is that a set of ideals are established in which members are trusted to uphold. This creates a sense of community within educational institutions to which students feel compelled to adhere. This is particularly appealing to the Thai environment as it would fit in to the collectivist frame of reference for which Thailand is renowned. 


\section{Conclusion}

This study has shown that while irrefutable conclusions regarding the Thai personality cannot be reached, it can be seen that certain aspects of the Thai character can influence a student's decision to commit academic dishonesty. Additionally, growing up in an environment where corruption is a tolerated and, in some cases, acceptable means of gaining benefits from society coupled with a lack of critical thinking skills cannot help but shape the Thai students' ethical frame of reference.

Through student questionnaires and teacher interviews it has been shown that students display high short-term orientation and dismiss the idea of placing any blame for their failings upon their teachers. Although students did not overtly admit to committing academic dishonesty, interviews with teachers supported the hypothesis that cheating occurs and is a serious problem at the university. Additionally, it was shown that there were divergent views among teachers regarding the reasons behind student cheating as well as opinions regarding the no-fail policy.

While cheating remains a seemingly insurmountable problem within Thai universities, there is hope for a stronger ethical framework if measures are undertaken with the goal of alleviating the importance placed upon grades and instilling a sense of community within schools by adopting an appropriate school honor code.

Competing interests

The author declare that they have no competing interests.

Authors' information

Bio Data:

David Young is a lecturer at Phra Nakorn Sri Ayutthaya Rajabhat University. He is also the author of eight books of fiction set in Thailand. He lives in Phra Nakorn Sri Ayutthaya.

Received: 21 March 2013 Accepted: 21 March 2013

Published: 2 April 2013

\section{References}

Bassett, P. (2004). Honor codes in schools. In National Association of Independent Schools. Retrieved from http://www. nais.org/Articles/Pages/Honor-Codes-in-Schools-145411.aspx.

Bunnag, S. (2007). Cheating at university on the rise. In The Bangkok Post. Retrieved from http://www.udonmap.com/ udonthaniforum/viewtopic.php?p=55624.

Bunnag, S. (2010). Cheating mars O-net exams. In The Bangkok Post. Retrieved from http://www.bangkokpost.com/ learning/education-features/33345/cheating-mars-o-net-exams.

Bunnag, S, \& Tumcharoen, S. (2002). Cheating by son of PM played down. In The Bangkok Post. Retrieved from http://www.accessmylibrary.com/coms2/summary_0286-25955057_ITM.

Cai, Y, \& Shannon, R. (2010). A comparative analysis of values and shopping patterns among Chinese and Thai mall shoppers. Paper presented at the Australian \& New Zealand Marketing Academy (ANZMAC) 2010 Conference. Retrieved from http://anzmac2010.org/proceedings/pdf/anzmac10Final00175.pdf.

Chutvachana, T. (2009). The memory span trap. In Asian Correspondent. Retrieved from http://asiancorrespondent.com/ 12446/thai-heart-and-mind-battle-the-memory-spantrap/.

Clark, DR. (2005). Long term vs. short term orientation. Retrieved from http://nwlink.com/ Donclark/leader/culture2.html.

Cleary, S. (2007). Don't panic, the kids are all right after all. In The Nation. Retrieved from http://www.nationmultimedia. com/2007/06/23/opinion/opinion_30037617.php.

Crittenden, V, Hanna, R, \& Peterson, R. (2009). The cheating culture: a global societal phenomenon. Business Horizons, 52, 337-346.

Daglas, C. (2003). Thai cheating scandal brings attention to academic-dishonesty issues. In The Badger Herald. Retrieved from http://badgerherald.com/news/2003/01/31/thai_cheating_scanda.php.

Davis, S, Drinan, P, \& Bertram-Gallant, T. (2009). Cheating in school: What we know and what we can do. West Sussex: John Wiley \& Sons, Ltd.

Dubas, J, \& Petersen, A. (2003). Depression: Adults, children and adolescents. In International Encyclopedia of Marriage and Family. Retrieved from http://www.encyclopedia.com/doc/1G2-3406900105.html.

Fry, G. (2002). Synthesis report: From crisis to opportunity, the challenges of educational reform in Thailand. Paper prepared for the Office of the National Education Commission and the Asian Development Bank.

Halligan, K. (2011). An examination of the no fail policy in Thailand and the effect on community relations. Language Testing in Asia, 1(2), 55-61.

Heagney, M. (2009). Can a school's culture of cheating be corrected? In The Columbus Dispatch. Retrieved from http:// www.dispatch.com/content/stories/faith_and_values/2009/08/21/FVcheat.ART_ART_08-21-09_B4_9HER40Q.html. 
His Yen, D. (1998). Learned helplessness. Retrieved from http://www.noogenesis.com/malama/discouragement/ helplessness.html.

Hofstede, G. (2001). Culture's consequences: Comparing values, behaviors, institutions, and organizations across nations (2nd ed.). Thousand Oaks, CA: Sage Publications.

Isaranurug, S, Nanthamongkolchai, S, \& Kaewsiri, D. (2005). Factors influencing development of children aged one to under six years old. J Med Assoc Thai, 1(88), 86-90.

Klausner, W. (2005). Thai identity revisited. Retrieved from http://www.thaiworld.org/en/include/print.php? text=89\&category_id=2\&print=true.

Klocke, K. (2011). Survey finds cheating among students at all GPA levels. In International Business Times. Retrieved from http://www.ibtimes.com/articles/244748/20111107/cheating-ucsd-pre-med-california-surveys.htm.

Komin, S. (1990). Psychology of the Thai people: Values and behavioral patterns. Retrieved from http://www.fulbrightthai. org/knowledge/read.asp?id=28\&type=culture.

Li, Z. (2011). Thailand ranks $80^{\text {th }}$ in the 2011 Corruption Perception Index. In Thailand Business News. Retrieved from http://thailand-business-news.com/business/33524-thailand-ranks-80th-in-the-2011-corruption-perception-index-cpi.

McCabe, D. (2005). Cheating: Why students do it and how we can stop them. In A Lathrop \& K Foss (Eds.), Guiding students from cheating and plagiarism to honesty and integrity (pp. 237-269). Westport, CT: Libraries Unlimited.

McCarty, CA, Weisz, JR, Wanitromanee, K, Eastman, K, Suwanlert, S, Chaiyasit, W, \& Brotman-Band, E. (1999). Culture, coping, and context: Primary and secondary control among Thai and American youth. Journal of Child Psychology and Psychiatry, 40,809-818.

Okan, Z. (2003). Edutainment: is learning at risk? British Journal of Educational Technology, 3(34), 255-264.

Patamadit, I, \& Bousquet, F. (2005). The Thai traditional learning process in folk culture: Implications for the companion modeling approach. In F Bousquet, G Trébuil, \& B Hardy (Eds.), Companion Modelling and Multi-agent System for Integrated Natural Resource Management in Asia (pp. 295-308). Los Banos, Philippines: IRRI Publications.

Poll. (2012). Poll: Corruption a major problem. In The Bangkok Post. Retrieved from http://www.bangkokpost.com/news/ local/273425/poll-corruption-is-a-biggest-problem.

Punyawan, W. (2010). Widespread cheating uncovered in Royal Thai Police exams. In Pattaya Daily News. Retrieved from http://www.pattayadailynews.com/en/2010/09/24/widespread-cheating-uncovered-in-royal-thai-police-exams/.

Saengwichai, D. (1998). The Khit-pen theological educational model: A new methodology for contextualizing theological education in Thailand. Retrieved from http://didache.nazarene.org/pdfs/AsiaPac03-Saengwichai.KhitPen_Theological_Model.pdf.

Saiyasombut, S. (2010). Thai corruption survey makes grim reading. In Asian Correspondent. Retrieved from http:// asiancorrespondent.com/42375/thai-corruption-survey-results-make-grim-reading/.

Scriven, M, \& Paul, R. (1987). Critical thinking as defined by the National Council for Excellence in Critical Thinking. Retrieved from http://www.criticalthinking.org/pages/defining-critical-thinking/766

Simkin, M, \& McLeod, A. (2009). Why do college students cheat? Journal of Business Ethics, 3(94), 441-453.

Songsriwittaya, A, Kongsuwan, S, Jitgarun, K, Kaewkuekool, S, \& Koul, R. (2009). Engineering students' attitude towards plagiarism: A survey study. Retrieved from http://www.ineer.org/Events/ICEEiCEER2009/full_papers/full_paper_212.pdf.

Thailand best top university ranking 2011. (2011). Webometrics. Retrieved from http://www.webometrics.info/sites/ default/files/Ediciones_anteriores/Top\%20500\%20Webometrics\%20Ranking\%20of\%20World\%20Universities\%20July $\% 202011 . x \mid s$.

Thailand remains a nest of corruption. (2011). The Bangkok Post. Retrieved from http://www.bangkokpost.com/news/ local/219194/thailand-remains-a-nest-of-corruption-.

Thailand students nabbed with mobile phones in shoes during exams. (2005). Textually.org. Retrieved from http://www. textually.org/textually/archives/2005/03/007333.htm.

Vanijaka, V. (2011). Bought grades, sold souls an all-access pass through the halls of higher learning. In The Bangkok Post. Retrieved from http:/www.bangkokpost.com/opinion/opinion/214089/bought-grades-sold-souls-an-all-accesspass-through-the-halls-of-higher-learning.

Visalo, P. (2008). When Buddhist monks cheat in exams. In The Buddhist Channel. Retrieved from http://www. buddhistchannel.tv/index.php?id=70,6289,0,0,1,0.

Weisz, J, Suwanlert, S, Chaiyasit, W, Weiss, B, Achenbach, T, \& Eastman, K. (1993). Behavioral and emotional problems among Thai adolescents: parent reports for ages 12-16. Journal of Abnormal Psychology, 3(102), 395-403.

Whitley, B. (1998). Factors associated with cheating among college students. Research in Higher Education, 3(39), 235-274.

Why Thailand is so corrupt. (2011). The Bangkok Post. Retrieved from http://www.bangkokpost.com/news/local/257882/ why-thailand-is-so-corrupt.

Wong-Anan, N. (2008). Watch out! Thai exam cheat triggers phone-watch ban. In Reuters. Retrieved from http://www. reuters.com/article/2008/03/05/us-thailand-cheating-idUSBKK4207420080305.

World Bank. (2011). Thailand: challenges and options for 2011 and beyond. Bangkok: Kevin MacDonald.

Young, D. (2010). Effects of culture on Thai learners of English. (Unpublished manuscript). Bangkok: Shinawatra University.

doi:10.1186/2229-0443-3-6

Cite this article as: Young: Perspectives on cheating at a Thai University. Language Testing in Asia 2013 3:6. 